\title{
BMJ Open Differences in infant and child mortality before and after the Great East Japan Earthquake and Tsunami: a large population-based ecological study
}

To cite: Tashiro A, Sakisaka K, Okamoto $\mathrm{E}$, et al. Differences in infant and child mortality before and after the Great East Japan Earthquake and Tsunami: a large population-based ecological study. BMJ Open 2018;8:e22737. doi:10.1136/ bmjopen-2018-022737

- Prepublication history for this paper is available online. To view these files, please visit the journal online (http://dx.doi org/10.1136/bmjopen-2018022737).

Received 22 March 2018 Revised 30 July 2018

Accepted 1 October 2018

\section{Check for updates}

(c) Author(s) (or their employer(s)) 2018. Re-use permitted under CC BY-NC. No commercial re-use. See rights and permissions. Published by BMJ.

${ }^{1}$ Graduate School of Environmental Studies, Tohoku University, Sendai, Japan ${ }^{2}$ Graduate School of Public Health, Teikyo University, Tokyo, Japan

${ }^{3}$ Department of Health and Welfare Management, University of Fukuchiyama, Kyoto, Japan

${ }^{4}$ Healthcare New Frontier Promotion Headquarters Office, Kanagawa Prefectural Government, Yokohama, Japan ${ }^{5}$ Division of Establishment for Graduate School of Health Innovation, Kanagawa University of Human Services, Yokosuka, Japan

Correspondence to

Dr Ai Tashiro;

atashiro11@gmail.com

\section{ABSTRACT}

Objectives To examine associations between access to medical care, geological data, and infant and child mortality in the area of North-Eastern Japan that was impacted by the Great East Japan Earthquake and Tsunami (GEJET) in 2011.

Design A population-based ecological study using publicly available data.

Setting Twenty secondary medical areas (SMAs) in the disaster-affected zones in the north-eastern prefectures of Japan (Iwate, Fukushima and Miyagi). Participants: Children younger than 10 years who died in the 20 SMAs between 2008 and $2014(n=1748)$. Primary and secondary outcome measures: Multiple regression analysis for infant and child mortality rate. The mean values were applied for infant and child mortality rates and other factors before GEJET (2008-2010) and after GEJET (2012-2014).

Results Between 2008 and 2014, the most common cause of death among children younger than 10 years was accidents. The mortality rate per 100000 persons was $39.1 \pm 41.2$ before $2011,226.7 \pm 43.4$ in 2011 and $31.4 \pm 39.1$ after 2011 . Regression analysis revealed that the mortality rate was positively associated with low age in each period, while the coastal zone was negatively associated with fewer disaster base hospitals in 2011. By contrast, the number of obstetrics and gynaecology centres $(\beta=-189.9, p=0.02)$ and public health nurses $(\beta=-1.7, p=0.01)$ was negatively associated with mortality rate per person in 2011.

Conclusions In 2011, the mortality rate among children younger than 10 years was 6.4 times higher than that before and after 2011. Residence in a coastal zone was significantly associated with higher child mortality rates.

\section{INTRODUCTION}

Natural disasters cause significant socioeconomic damages and large-scale deaths. Compared with adults, infants and children are more vulnerable during and after natural disasters. ${ }^{1}$ On 11 March 2011, the Great East Japan Earthquake and Tsunami (GEJET) stuck North-Eastern Japan, and the tsunami that followed caused massive damage and a high death rate, particularly of children in

\section{Strengths and limitations of this study}

- This study integrates infant and child mortality data with GIS information to assess the influence of damages caused by a natural disaster on child healthcare.

- A longitudinal study of statistical as well as geological distribution was used to evaluate differences in child mortality before, during and after 2011 by sex, age group and the secondary medical area in the disaster-affected zone.

- Since this ecological study used publicly available data, we were not able to assess and identify individual social and economic factors influencing child mortality during the study period.

coastal zones due to several reasons, including drowning. Particularly among children in coastal zones, in 2011, the death rate of children younger than 10 years in areas affected by the earthquake and tsunami increased by $40 \% .^{2}$ Given this demographic profile, the influence of natural disasters on mortality, particularly of infants and children, is not well understood.

Areas affected by the earthquake and tsunami were generally poorer. The disaster significantly crippled the medical resources and healthcare services for infants and children. Although Hurricane Katrina in 2005 and the Southern California wildfires in 2017 reinforced the need to provide paediatric unit-specific guidelines to medical personnel responding to disasters in both hospital and prehospital settings in USA, ${ }^{3-5}$ as of 2011, the lack of a regional disaster medical management plan in Japan resulted in difficulty in responding to the healthcare needs of children at risk. Disaster medical assistance teams (DMATs), which were launched in 2005 were unable to respond to expectant or nursing mothers and children due to the lack of an information sharing system and network with 


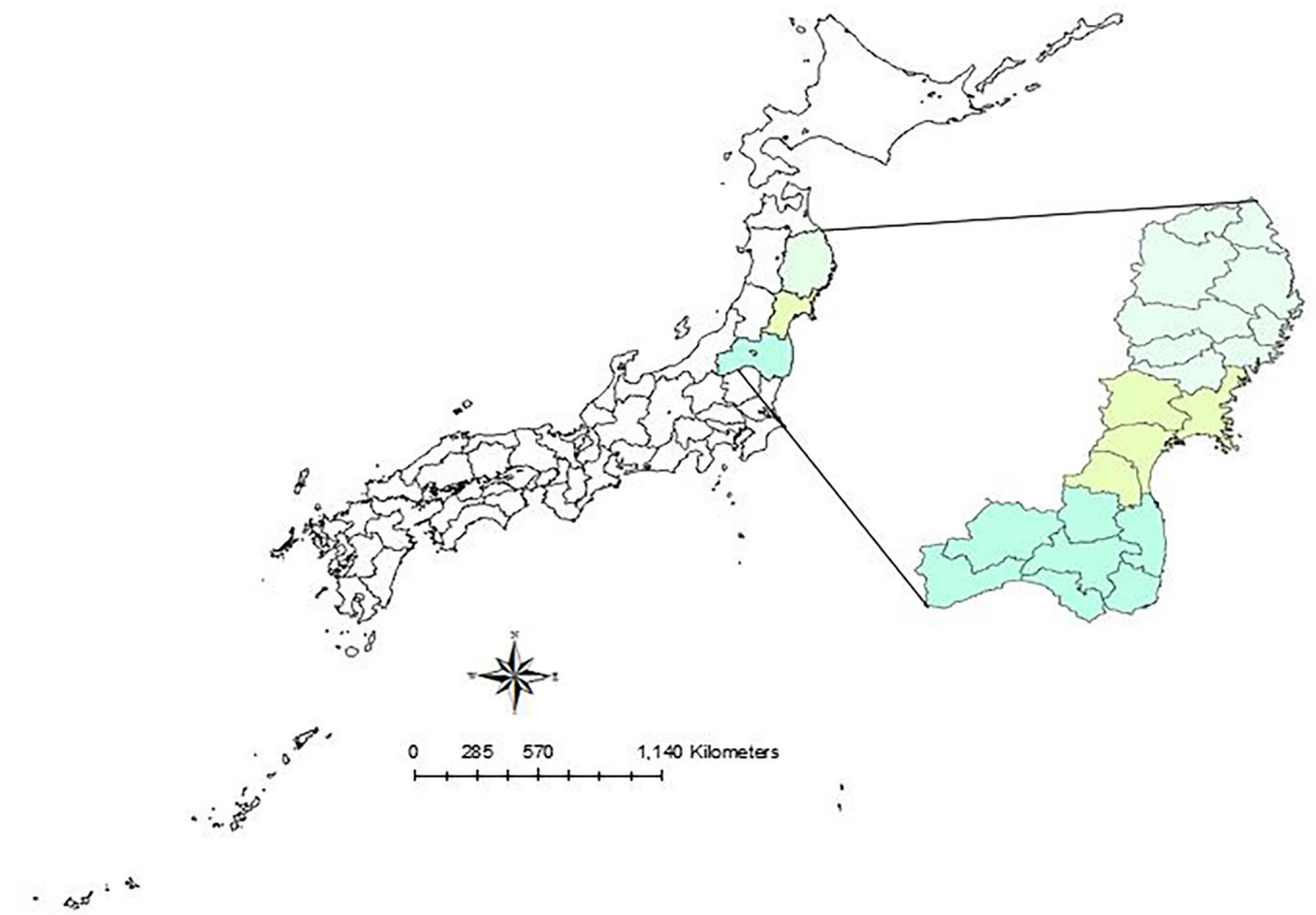

Figure 1 Map of the study area. Municipalities severely damaged by the tsunami were included in the analysis and classified into three areas according to their geographical characteristics. The boundary indicates secondary medical areas (SMAs) in each prefecture.

local hospitals, clinics and emergency-response organisations. ${ }^{6-8}$ Regarding the establishment of a liaison system between DMATs and local medical care organisations, only a few prior studies determined the influence of disaster on child mortality and examined the association between areas with poor medical resources and how to manage preventable child deaths. ${ }^{9} 10$

In this paper, we investigated the dynamics of infant and child mortality (age 0-9 years) in North-Eastern Japan before and after 2011. This study aimed to examine the associations between the different characteristics of medical care, including the preparedness of obstetrics and gynaecology (Ob-Gyn) centres, paediatricians and public health nurses (PHNs), and the geological distribution of hospitals/clinics. We also determined the influence of changes in normal and emergency conditions on infant and child mortality. Empirical evidence on these different aspects of large population-based ecological time series regarding infant and child mortality can contribute to the establishment of a local liaison system for paediatric and perinatal medical care during disasters.

\section{METHODS}

\section{Study population}

Due to the influence of geographical and social characteristics on patterns of inundation and casualties, we compared data from Iwate, Miyagi and Fukushima. These regions share common topographical features, namely, a deeply indented coastline with narrow flatlands bordered by sea and mountains, which increases their vulnerability to damage caused by tsunami. The total number of clustered secondary medical areas (SMAs) was 20 (figure 1). From 2008 to 2014, according to the Data Warehouse for Healthcare and Welfare Plan (DWH) database, a total of 1748 deaths occurred among children aged $0-9$ years in Iwate, Fukushima and Miyagi ( $0-4$ years: 1345 ; $5-9$ years: 403). In 2011, a total of 717 deaths occurred among children aged 0-9 years in the three prefectures (Iwate: 168; Miyagi: 452; and Fukushima: 97).

\section{Study site}

Regarding medical resources, we mapped the location of disaster base hospitals (DBHs) in figure 2, including core disaster medical hospitals (CDMHs) and local disaster medical centres (LDMCs) and added data from other medical facilities, such as perinatal medical centres (PMCs), paediatric clinics and Ob-Gyn clinics in figure 2A. We also gave a $10 \mathrm{~km}$ margin from each $\mathrm{DBH}$ and observed the range of coverage of those medical facilities in figure 2B. Most SMAs had DBHs except the IwateChubu and Soso areas. Meanwhile, the coastal zones in Iwate, Kuji, Miyako, Kamaishi and Kesen also had DBHs. Most of these DBHs combined PMC function but had few paediatric units. Most paediatric units were distributed out of the $10 \mathrm{~km}$ margin in Iwate. In Miyagi, most DBHs were centralised in the inland zone and Sendai, which is the prefectural capital of Miyagi.

As of 2014, the numbers of full time doctors and clinics were as follows: paediatric clinics, 824 (Iwate: 290, Miyagi: 404, Fukushima: 497); paediatricians, 1191 (Iwate: 290, Miyagi: 404, Fukushima: 497); Ob-Gyn clinics, 216 (Iwate: 
(A)

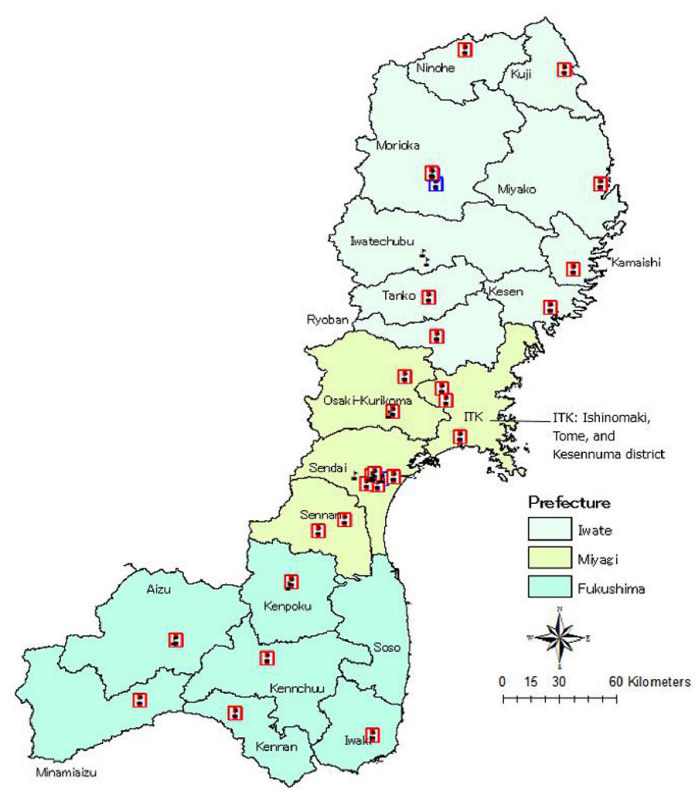

(B)

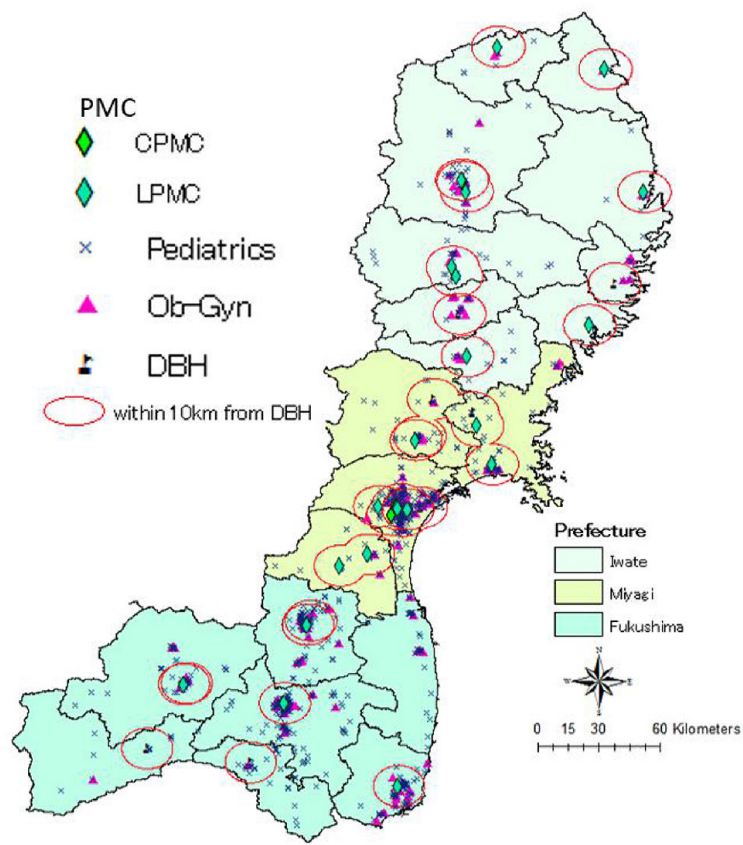

Figure 2 (A) Location of $\mathrm{DBH}$, including $\mathrm{CDMHs}$ and LDMCs. (B) Medical facilities. CDMH, core disaster medical hospital; DBH, disaster base hospital; LDMC, local disaster medical centre; PMC, perinatal medical centre (central and local).

81, Miyagi: 49, Fukushima: 88), Ob-Gyn doctors, 332 (Iwate: 124, Miyagi: 62, Fukushima: 146). Regarding PMC, Iwate and Miyagi had 10 each, and Fukushima had 5. Meanwhile, regarding disaster medical facilities, Iwate had 11 DBHs (2 CDMHs and 9 LDMCs); Miyagi had 13 DBHs (1 CDMH and 12 LDMCs) and Fukushima had 8 DBHs (1 CDMH and 7 LDMCs). In Fukushima, Soso did not have a DBH, as shown in figure 2. While each DBH was located in inland areas in each SMA except Iwaki, in the coastal zone, paediatric units were located along the coast and did not cover the $10 \mathrm{~km}$ margin of the DBH. Iwaki had a DBH and centralised PMCs for neighbouring coastal zones.

\section{Study design and setting}

We performed a population-based ecological study using data from the Statistical Bureau of Japan $(e-\text { Stat })^{11}$ and from DWH. ${ }^{12} e-$ Stat is the official portal for Japanese government statistics. Each database is produced by all ministries in the government. e-Stat records ecological data of several categories, such as prefectures, age groups and sex, to analyse the mortality rates of specific areas and age groups. However, we could not complete the analysis by only using data from $e$-Stat. Thus, we also used data from the DWH database, which categorises more specific factors, such as medical administration, health centre area and municipal data, such as the number of PHNs; death by age, sex and year; and categorised medical areas. In Japan, medical administration areas are broadly divided into three units: each municipality is designated as a primary medical area, a combination of two municipalities is designated as an SMA and a prefecture is designated as a tertiary medical area. Under the Medical Care Act, SMA is defined as the essential unit for healthcare planning, within which all necessary care shall be provided. Based on this principle, we used the SMA as the unit of analysis in our ecological study design to identify the inequality of medical resources and to determine the influence of available medical resources on infant and child mortality.

Regarding medical resources, our study used the database of the Japan Medical Analysis Platform (JMAP), ${ }^{13}$ Japan Association of Obstetricians and Gynaecologists $\left(\right.$ JAOG) ${ }^{14}$ and Medicare Information Laboratory (MIL). ${ }^{15}$ JMAP collects medical information and institutional data nationwide. We obtained the number of medical doctors by detailed categories. JAOG records information from comprehensive/local perinatal maternal child medical centres and PMCs. Meanwhile, the MIL of the Ministry of Health, Labour and Welfare records a list of DBHs, including CDMHs and LDMCs. A DBH is a disaster-ready hospital, which has a function of supporting local medical institutions and accepts the seriously ill and seriously disabled. DBHs are placed as hospitals to play a central role in medical care relief activities during disasters. In principle, each prefecture should have more than one CDMH, and each SMA should have more than one LDMC.

We analysed data from e-Stat, DWH, JMAP, JAOG and MIL in three prefectures (Iwate, Fukushima and Miyagi) from 2008 to 2014. We investigated damages and impacts of disasters during a 7-year period, that is, before GEJET (2008-2010), 2011 and after GEJET (2012-2014). We chose these three prefectures because they were the most severely affected prefectures in 2011, and more than $99 \%$ of all deaths were recorded in these areas. ${ }^{16}$ Integrating data from $e-$ Stat, DWH, JMAP, JAOG and MIL enabled us to identify mortality rates by sex, age group and region. 


\section{Measurements}

We analysed infant and child mortality rates by sex, age group (0-4 years and 5-9 years) and SMA in Iwate, Miyagi and Fukushima. The leading causes of mortality by sex, study span and SMA were examined for each age group. To calculate death rates per 100000 inhabitant children younger than 10 years, official resident registration data for inhabitants were used. We calculated the age-specific death rate using the administrative reports of resident registries of municipalities in $e$-Stat and $\mathrm{DWH}$ as denominators. The specific causes of death for ages 0-4 years and 5-9 years were ranked up to fifth from 2008 to 2014 in Japan. Demographic and ecological characteristics were also analysed to examine deaths caused by natural disasters. To determine the potential effect of disasters on the different SMA mortality rates, we analysed ecological characteristics using geographical information systems. ${ }^{17}$ We mapped the bar graph of infant and child deaths. We also mapped the location of medical facilities, such as paediatric units, Ob-Gyn clinics, DBHs and PMCs using ArcGIS V.10.4 (Esri, Redlands, California, USA). ${ }^{18}$ Also, to determine the $\mathrm{DBH}$ coverage of neighbouring medical facilities and clinics, we gave a $10 \mathrm{~km}$ margin from each DBH location.

\section{Patient and public involvement}

In this study, patients and the public were not involved.

\section{Statistical analysis}

Quantitative variables are presented as mean \pm SD. We conducted multiple regression analysis of infant and child mortality rates according to each of the classified periods (before 2011, during 2011 and after 2011). Regression model analyses were applied for infant and child mortality rates before GEJET (2008-2010) and after GEJET (20122014). To examine the associations between mortality rate and ecological characteristics, we included 12 variables in the regression models. Dummy variables were used for sex, age group ( $0-4$ years vs 5-9 years), locations of SMAs, locations of DBHs and prefecture. Meanwhile, the continuous variables were the number of $\mathrm{DBHs}$, paediatric units, paediatricians per 100000 population, Ob-Gyn clinics, Ob-Gyn doctors per 100000 population and PHNs. Statistical significance was tested at a two-sided significance level of 0.05 , and all CIs were reported as two-sided values with a confidence level of 95\%. Statistical analyses were performed using Stata V.14.0 (Stata Corp, College Station, Texas, USA). ${ }^{19}$

Table 1 summarises the baseline characteristics of medical resources in Iwate, Miyagi and Fukushima. Data were expressed as mean \pm SD As shown in table 1 , medical resources in Iwate were significantly fewer than those in other prefectures. In particular, the mean number of paediatric clinics in Iwate was lower than those in other prefectures (Iwate: 12.8, Miyagi: 80.3 and Fukushima: 99.0). The national average of paediatricians per 100000 population was 17.9 and that of Ob-Gyn doctors was 3.94 in 2015. Compared with this data, those of the study areas were lower.
Table 1 Baseline characteristics of medical resources in affected areas of the three prefectures

\begin{tabular}{|c|c|c|c|}
\hline $\begin{array}{l}\text { Medical } \\
\text { resources }\end{array}$ & Iwate & Miyagi & Fukushima \\
\hline Paediatric clinic & $12.8(14.3)$ & $80.3(97.6)$ & $99.0(144.6)$ \\
\hline $\begin{array}{l}\text { Paediatricians } \\
\text { per } 100000 \\
\text { population }\end{array}$ & $8.0(2.5)$ & $12.5(1.6)$ & $23.8(8.9)$ \\
\hline Paediatrician & $32(60.4)$ & 101 (123.9) & $70(57.5)$ \\
\hline PMC & $1.1(0.9)$ & $2.5(1.7)$ & $0.7(0.8)$ \\
\hline $\begin{array}{l}\text { Ob-Gynper } 100 \\
000 \text { population }\end{array}$ & $2.9(1.9)$ & $2.7(0.5)$ & $3.6(1.1)$ \\
\hline Ob-Gyn clinic & $4.9(5.9)$ & $22.0(32.1)$ & $19.8(30.1)$ \\
\hline Ob-Gyn doctor & $7(8.6)$ & $37(56.4)$ & $17(18.4)$ \\
\hline \multicolumn{4}{|l|}{ PHN } \\
\hline $\begin{array}{l}\text { PHN before } \\
2011\end{array}$ & N/A & $\mathrm{N} / \mathrm{A}$ & $\mathrm{N} / \mathrm{A}$ \\
\hline PHN 2011 & $128(55.8)$ & 365 (92.3) & 204 (119.3) \\
\hline PHN after 2011 & $132(54.6)$ & $371(86.1)$ & 213 (99.9) \\
\hline
\end{tabular}

The value of each medical resource was expressed as mean (SD) before 2011 (2008-2010), during 2011 and after 2011 (2012-2014). Ob-Gyn, obstetrics and gynaecology; PMC, perinatal medical centre; PHN, public health nurse.

The mortality rate per 100000 population as classified according to the medical care area (SMA) is shown in figure 3. From this figure, the mortality rates before and after 2011 were only minimally different among the SMAs, and were lower than 100 per 100000 population. By contrast, the rates were significantly higher in 2011 than in the other periods. The mortality rates were higher in coastal zones, such as Ishinomaki-Tome-Kesennuma (ITK), Kamaishi, Kesen and Miyako, than those of other SMAs in Iwate. In particular, the mortality rate for children aged 0-4 years in Kamaishi was 1469.5 per 100000 population, which was the highest among all 20 SMAs.

Figure 4 shows the influence of SMA location on infant and child mortality by age group, sex and period. From this mortality box plot, we can see that the mortality rate of children younger than 10 years was significantly higher than those before and after 2011 in coastal zones. Moreover, the mortality rate of children aged $0-4$ years was higher than that of children aged 5-9 years. Furthermore, the mortality rates of boys were higher than those of girls in the coastal zone. Meanwhile, regardless of age, sex and period, mortality rates followed a similar pattern in the inland zone, in which each mean mortality rate was not statistically different.

A total of 1748 deaths of children aged 0-9 years were confirmed in the 20 SMAs from 2008 to 2014 in the affected area. Table 2 summarises the mortality rate of children younger than 10 years according to the availability of medical resources in target areas before, during and after 2011. A total of 1062 infant and child deaths were identified; the mean death rate before 2011 was 


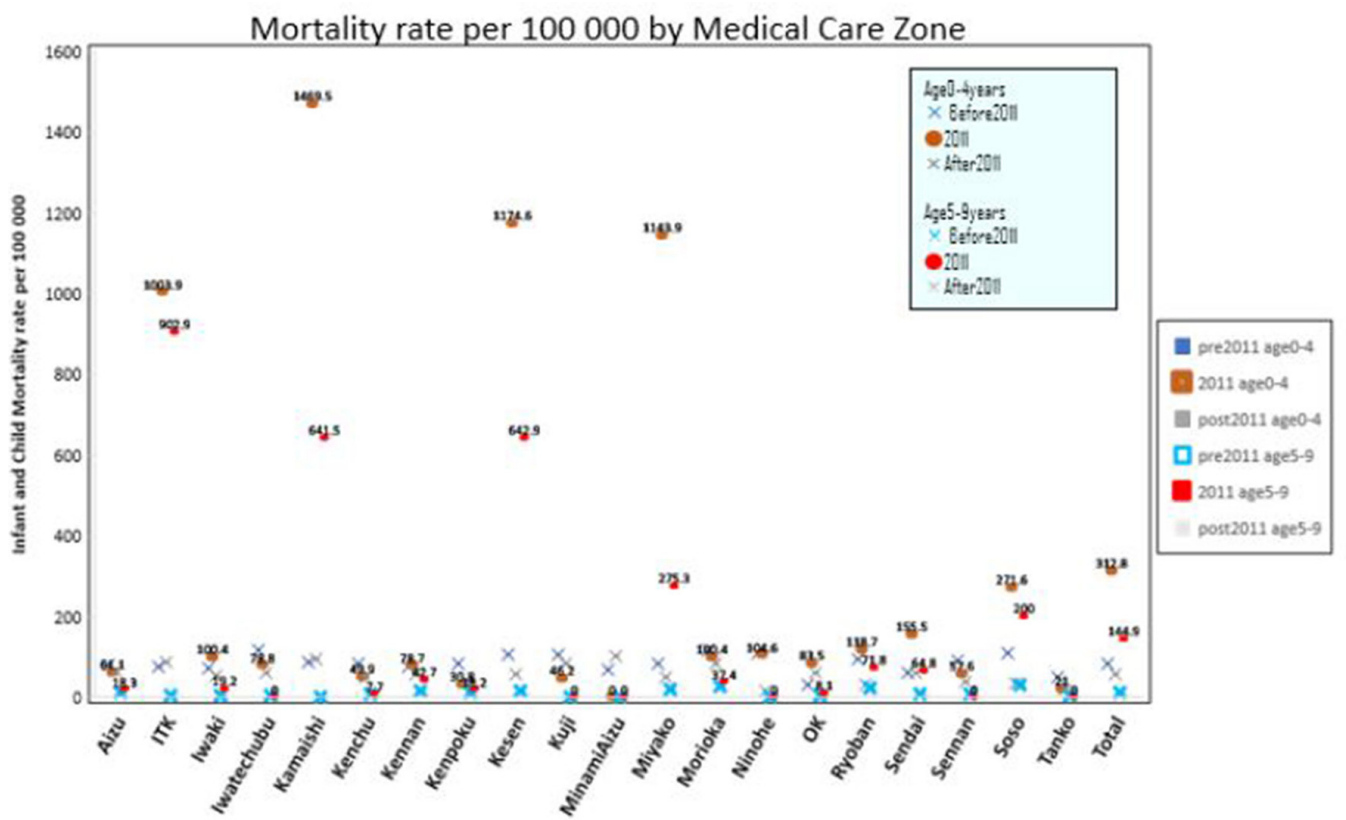

Figure 3 Mortality rate per 100000 population as classified according to medical care area.

191, the number of deaths in 2011 was 717 and the mean death rate after 2011 was 152.7. As shown in table 2, the values are presented as numbers or means of mortality rate by individual attributes (sex, age group, mortality rate per 100000 population, region and location of DBH) for infants and children by periods. The results show no statistically significant difference in the proportion of death rates as analysed according to sex from 2008 to 2014. However, the number of male deaths in 2011 was 3.5 times higher than before 2011 and 4.2 times higher than after 2011. The rate of female deaths was 4.1 times higher than before 2011 and 5.3 times higher than after
2011. Regarding age group, in each period, the number of deaths of children aged 0-4 years was higher than that of children aged 5-9 years. Proportionate gaps of death were noted between those aged $0-4$ years and 5-9 years before and after $2011(72.8-74.6 \%) \%)$. However, the gaps decreased to $25.2 \%$ in 2011 . In 2011, the mortality rate in the coastal zone was 11.7 times higher than in the inland zone. Meanwhile, the mortality rate in the DBHs along the coast was 10 times higher than in those not along the coastal zone.

Figure 5 presents the mortality distribution of children aged $0-9$ years in the affected areas before, during and

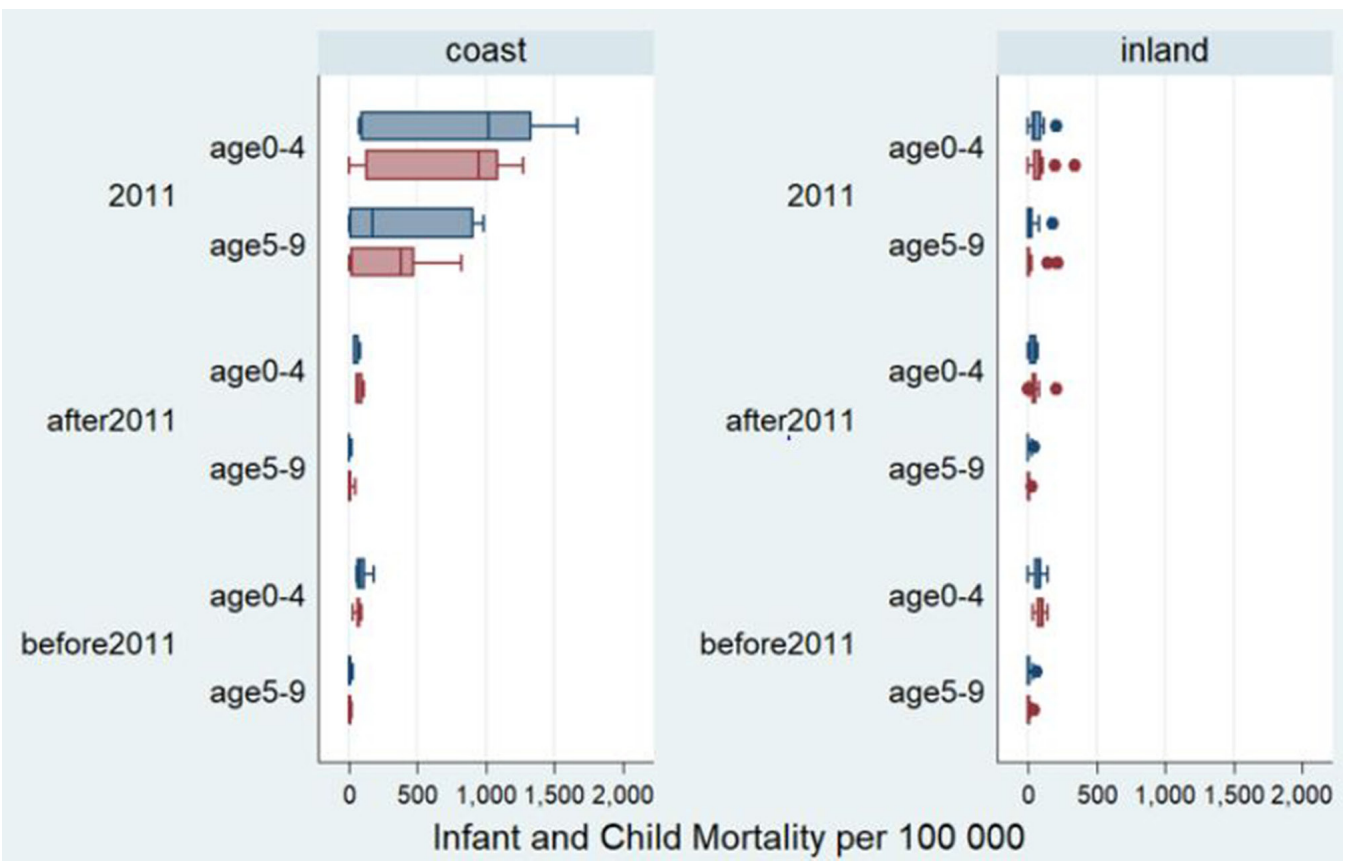

Figure 4 Influence of secondary medical area (SMA) location on infant and child death by age group, sex and period*. 
Table 2 Population mortality of children younger than 10 years and medical resources in the target areas before, during and after 2011

\begin{tabular}{|c|c|c|c|}
\hline & Before 2011 & & After 2011 \\
\hline & 2008-2010 & 2011 & 2012-2014 \\
\hline \multicolumn{4}{|l|}{ Sex } \\
\hline Male $(n=550)$ & $104(54.3)$ & $361(50.3)$ & $85(55.9)$ \\
\hline Female $(n=511)$ & $88(45.7)$ & $356(49.7)$ & $67(44.1)$ \\
\hline \multicolumn{4}{|l|}{ Age group } \\
\hline $0-4$ years $(n=748)$ & $167(87.3)$ & $449(62.6)$ & $132(86.4)$ \\
\hline $5-9$ years $(n=313)$ & $24(12.7)$ & $268(37.4)$ & $21(13.6)$ \\
\hline Mortality rate per $100000(n=1067)^{\star}$ & $39.1 \pm 41.2$ & $226.7 \pm 43.4$ & $31.4 \pm 39.1$ \\
\hline \multicolumn{4}{|l|}{ Secondary medical area* } \\
\hline Coastal $(n=795.8)$ & $41.8 \pm 42.3$ & $456.5 \pm 489.4$ & $33.9 \pm 34.0$ \\
\hline Inland $(\mathrm{n}=265.9)$ & $36.8 \pm 40.5$ & $38.7 \pm 44.7$ & $29.4 \pm 36.5$ \\
\hline \multicolumn{4}{|l|}{ Location of $\mathrm{DBH}^{*}$} \\
\hline Not along the coast $(n=175.2)$ & $37.0 \pm 41.5$ & $54.9 \pm 70.6$ & $27.0 \pm 34.0$ \\
\hline Along the coast $(n=886.5)$ & $42.9 \pm 40.7$ & $545.7 \pm 519.6$ & $39.5 \pm 35.2$ \\
\hline
\end{tabular}

Values are shown as $\mathrm{n}(\%)$ or mean \pm SD.

*Each mean of values presents factors potentially affecting the mortality rate, and variables were analysed using the student $t$-test at the $5 \%$ level of significance. All values were statistically significant at $\alpha=0.05$.

$\mathrm{DBH}$, disaster base hospital.

after 2011 by SMA. As shown in figure 5A, the number of deaths in Sendai was the highest, with 49 infant deaths in 2011 (boys: 21, girls: 28). ITK recorded 25 deaths in 2011. Tangentially, the number of male deaths was higher than female deaths, and the mortality rate was remarkably high along the coastal zones, particularly in 2011. As shown in figure $5 \mathrm{~B}$, among children aged $1-4$ years, the number of deaths before and after 2011 was lower than that in 2011. Among children aged 1-4 years, the number of deaths in ITK was the highest at $123(42.8 \%)$ out of the total 237 deaths in 2011. In particular, 45 (36.6\%) out of the 123 children who died were 3 years old. Among children aged 5-9 years, 268 died in 2011 (figure 5C). Similar to the mortality rate of those aged 1-4 years, the child mortality rate among those aged 5-9 years was also the highest in ITK at $145(54.1 \%)$ in 2011.

The top five causes of child mortality among children aged 0-9 years from 2008 to 2014 are shown in table 3 . Before and after 2011, congenital deformities were the primary cause of death among those aged 0 years in Japan (mortality rate $=81.3 \%$ ). Accidental death was ranked fifth before 2011, but ranked third in 2011 (mortality rate $=18.7 \%$ ). Among children aged 1-4 years, congenital deformities were also the primary cause of death except in 2008 and 2011 (mean mortality rate $=3.8 \%$ ). The mean rate of accidental death was $3.8 \%$ in 2008 and $9.1 \%$ in 2011. Meanwhile, accident was the primary cause of death among children aged 5-9 years from 2008 to 2013. The mortality rate due to natural disasters in 2011 was three times higher than that in other periods.

Sex, age group, the location of SMA, prefecture, $\mathrm{DBH}$, and the number of paediatric clinics per 100000 population, paediatricians, Ob-Gyn clinics, Ob-Gyn clinics per 100000 population, Ob-Gyn doctors and PHNs were tested for their association with infant and child mortality in the 20 SMAs (table 4). In this analysis, no statistically significant differences $(p>0.05)$ in the mortality rate regarding sex were noted before and after 2011. By contrast, significant differences were noted in child mortality as assessed according to age group. The mortality rate of children aged $0-4$ years was higher than those aged 5-9 years before, during and after 2011 $(p<0.01)$. In 2011 , the mortality rate was positively associated with the location of DBH, the number of DBHs and the number of PHNs in the 20 SMAs, indicating that in 2011, the occurrence of the natural disaster and existence of fewer medical resources were associated with increased infant and child mortality rates. By contrast, the mortality rate was negatively associated with the number of Ob-Gyn centres in 2011, indicating that a higher number of Ob-Gyn centres was associated with decreased infant mortality rate $(\beta=-189.9, \mathrm{p}=0.02)$.

\section{DISCUSSION}

The results of this analysis indicate the need to improve the accessibility of local medical facilities, simulate a transportation scenario during emergency situations and preassign residents to local hospitals during emergencies. ${ }^{20}$ However, previous studies did not focus on the influence of the spatial ecology on infant and child mortality. Access to medical care for infants and children can be improved by establishing a liaison system with the 

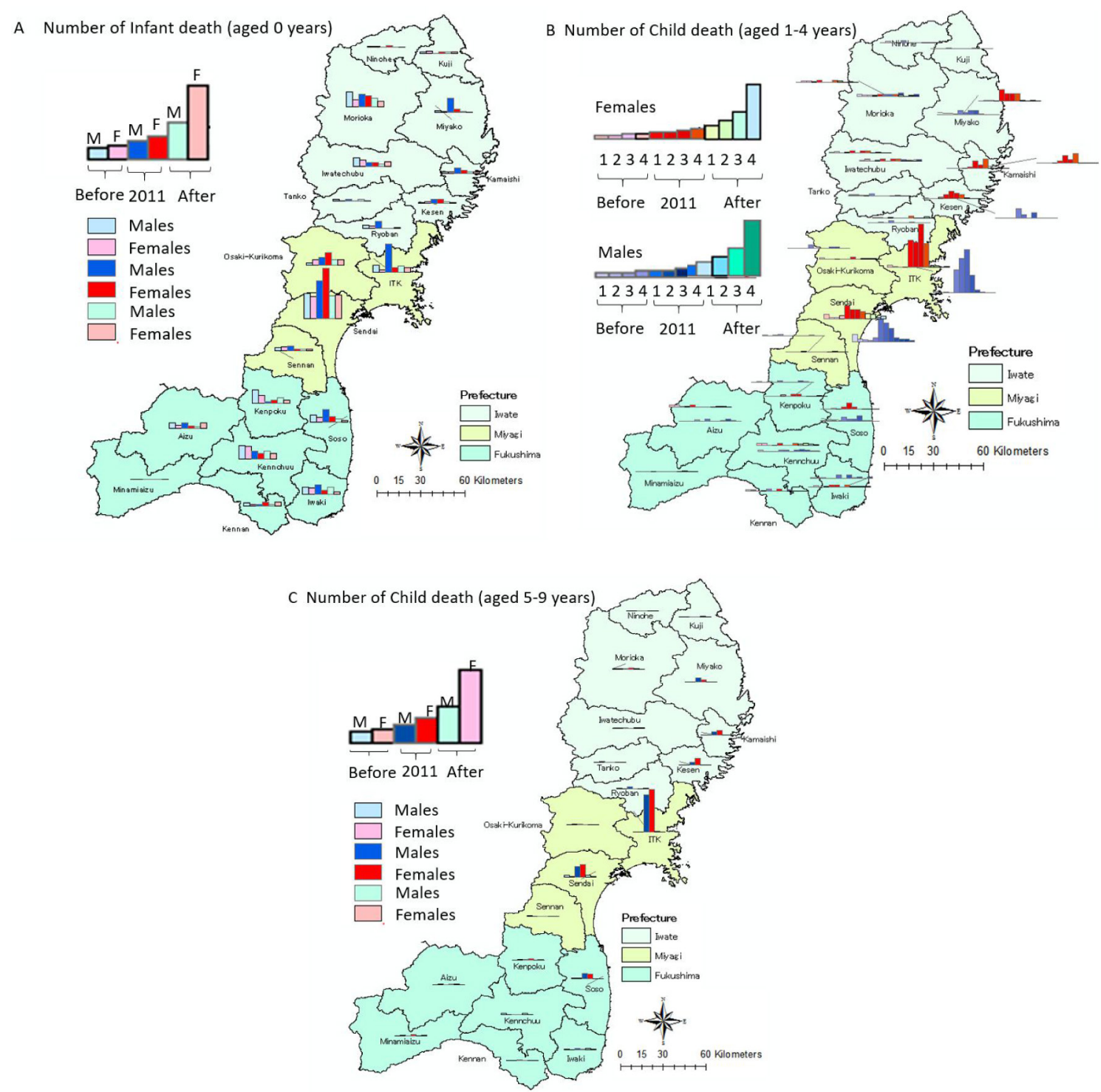

Figure 5 Mortality distribution among children aged 0-9 years in affected areas in 2011 by secondary medical area (SMA). (A) Number of infant deaths (aged 0 years). (B) Number of infant deaths (aged 1-4 years). (C) Number of infant deaths (aged 5- 9 years).

local childcare system to compensate for the potential lack of healthcare resources.

This study revealed mortality differences between normal and abnormal periods, that is, before, during and after the 2011 earthquake and tsunami by sex, age group and SMA. Disaster impact on child mortality was associated with abnormalities. Several studies have reported that the availability of medical resources in a prefecture affects the rate of child mortality, particularly in Iwate that has a poor medical service system; as such, there is the need to amend the evaluation standards of existing medical centres. ${ }^{21}{ }^{22}$ Iwate needs to support the recovery of children and their caregivers during and after the March 2011 GEJET. Another previous study reported that medical facilities are forced to integrate or discontinue due to the declining population. The policy to control the medical expense due to worsening fiscal conditions, loss of medical liaison between medical education institutions and regional/rural hospitals was also associated with imbalanced medical resource allocation. ${ }^{21}$ Developing obstetrics and disaster preparedness is an urgent issue for proper childcare accessibility (eg, information on evacuation, available hospitals, preparation in and for a disaster, and geographical materials) in disaster-affected rural areas. Based on the lessons learnt from the absence of liaison between DMATs and local medical care organisations, there was a demand to set a liaison system for paediatric and perinatal medical care during disasters in 2016.

The Child Care, Emergency Preparedness Toolbox, developed by the General Services Administration ${ }^{23}$ details how to deal with childcare and support liaison systems. However, Japan has not established an official childcare emergency disaster plan yet, although an information service for infants and perinatal disaster liaison is currently being studied. Few studies have focused on the effect of employing PHNs to mitigate child health risk. 


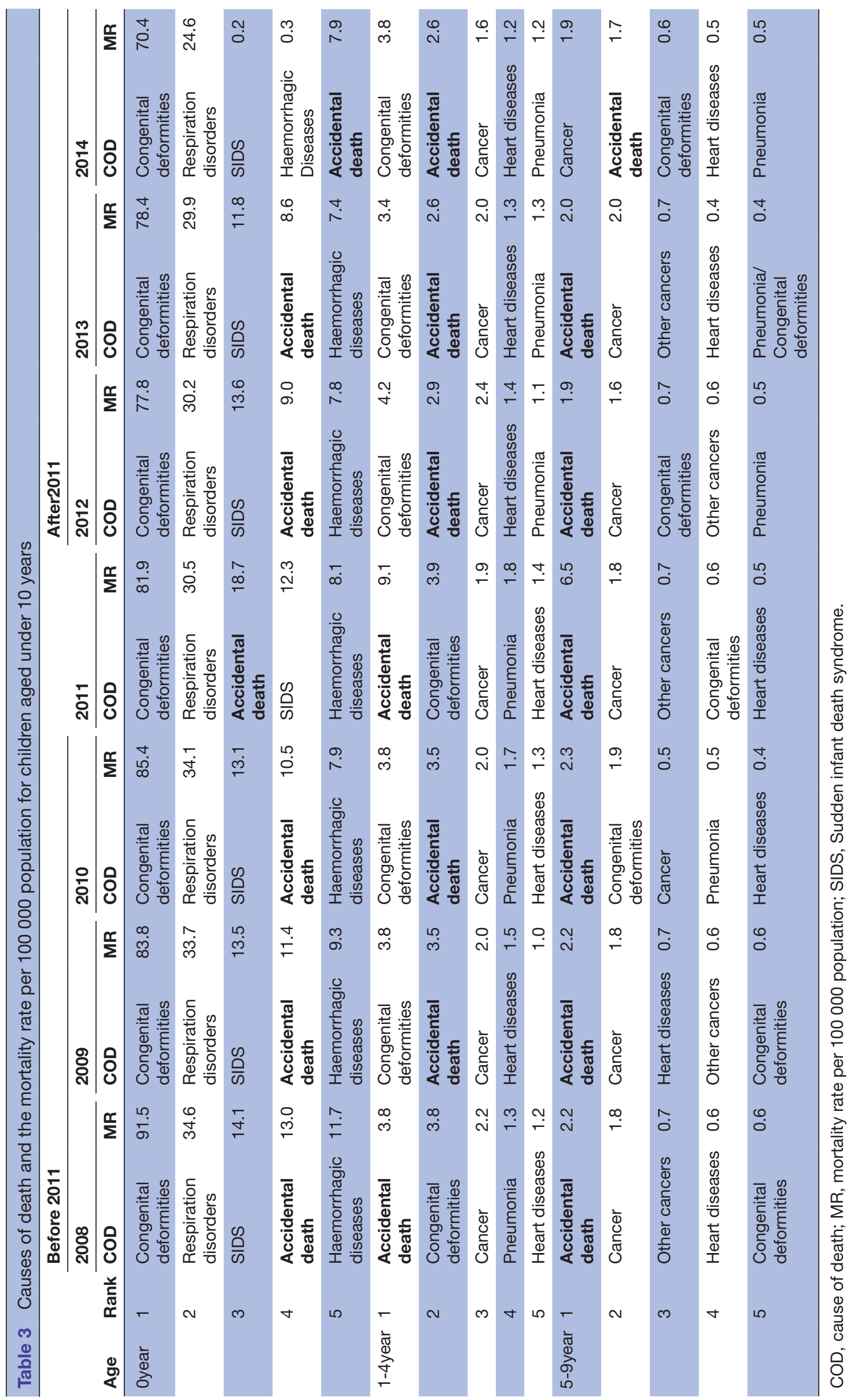




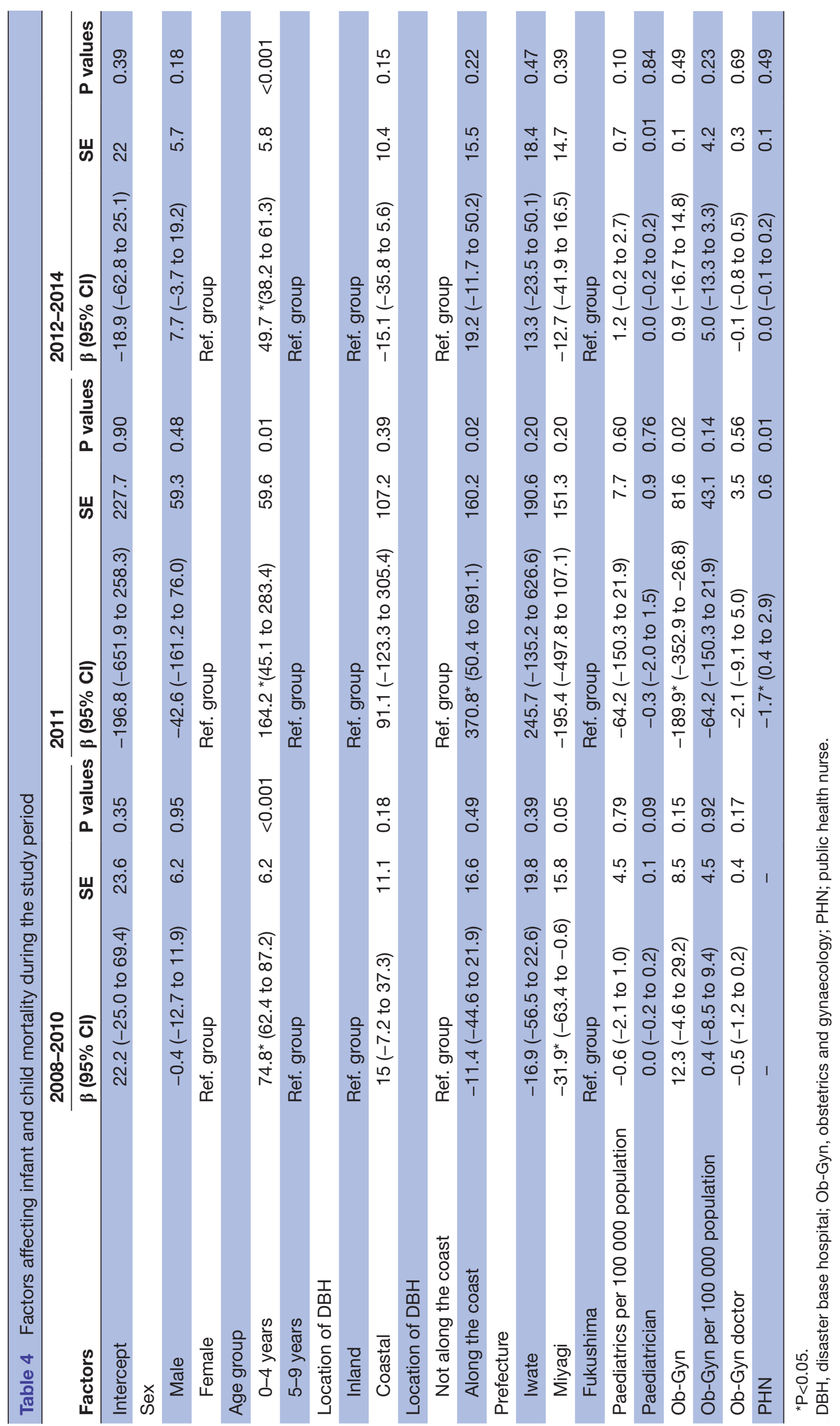


However, this result suggests that lack of obstetric units following a disaster made proper infant and childcare difficult. This study showed that grasping geographical medical resource distribution allows the enhancement of information liaison between health systems and medical units. To establish the liaison system, the numerous issues faced by disaster-affected individuals should be comprehensively addressed, and management should include enhancing the support structure, schemes to form communities, reconstruction of the disaster-affected areas, support for children and a system for sharing of information among healthcare infrastructures.

\section{Principal findings}

We observed that healthcare disparities by region remained statistically significantly associated with infant death. A total of 7 out of the $32 \mathrm{DBHs}$ located in the coastal zones were related to the risk of infant and child death in 2011; the child mortality rate was higher in coastal zones than that in the inland zones. From 2008 to 2012, accidents was in the top five causes of death among children aged 0-9 years. This result indicated that infants and children are exposed to accidents regardless of disaster outbreaks. In 2011, we found that the mortality rate in the coastal zone was 10 times higher than that in the inland zone. The mortality rate in 2011 increased 11-fold compared with that before and after 2011 when no tsunami had occurred. Furthermore, the mortality rate of children younger than 5 years was 164.2 times higher than that of children younger than 10 years in 2011.

\section{The accuracy of the case, exposure and outcome identification}

Our study analysed ecological data collected from the databases of $e$-Stat, DWH, JMAP and MIL which are widely used databases in Japan. However, misclassification of the data is possible, and the definition of the point where and how to count the number of migrants and immigrants is uncertain. Regarding general practitioners, paediatricians and Ob-Gyn doctors, we applied data only registered in JMAP. Data for mortality rate were calculated via the Residential Basic Book in the SMAs. As such, data of some infants and children may be missing. However, these data are official reports from the Japanese government. Thus, the validity of our calculated data is guaranteed.

\section{Study limitations}

Our study has several limitations. First, for 2008-2010 and 2012-2014, the mean data of 3 years were used in the analysis. As such, some inconsistencies may be present from the real data for each year. Nevertheless, the period analysed in the current study appears to be long enough to identify the causes of death and determine the ecological characteristics related to the mortality of children younger than 10 years. The changing trends in human casualties caused by north-eastern disasters indicated that ecological factors are associated with childhood mortality. Second, the study failed to include individual social and economic factors related to deaths due to natural disasters. Vulnerability, such as the effects of natural disasters on health, depends on personal characteristics, including the location of residence, age, income, education and disability, as well as economic factors, including socioeconomic status of parents and the budget of the healthcare facilities in each SMA during disasters. ${ }^{24}{ }^{25}$ Our study did not consider these factors during the analysis due to the limitations of population-based ecological data. Furthermore, many people were killed by the tsunami on 11 March 2011, but we could not estimate the biased results on the date because we obtained only annual data. There might exist location bias of DBH in coastal areas. We should also have focused on normal days of accidents. However, we used annual data and could only compare normal accident spans before and after 2011 and abnormal accidents in 2011. The limitation, however, applies to most previous studies that assessed the impacts on mortality of children younger than 10 years using ecological data.

Contributors AT designed the study and methodology, conducted the analysis and drafted the manuscript. KS and HY assisted in manuscript preparation and revised the draft. EO provided data sources, study materials and revised the manuscript. All authors read and approved the final manuscript.

Funding This work was supported by the JSPS KAKENHI Grant Number 17K12623 and Japan Agency for Medical Research and Development and "Personal Health Record (PHR) Research Project, PHR Model for Supporting Pregnancy, Delivery, and Childbearing" (FY 2016-2018); Grant Number JP18ls0110001.

Competing interests None declared.

Patient consent Not required.

Provenance and peer review Not commissioned; externally peer reviewed.

Data sharing statement No additional data are available.

Open access This is an open access article distributed in accordance with the Creative Commons Attribution Non Commercial (CC BY-NC 4.0) license, which permits others to distribute, remix, adapt, build upon this work non-commercially, and license their derivative works on different terms, provided the original work is properly cited, appropriate credit is given, any changes made indicated, and the use is non-commercial. See: http://creativecommons.org/licenses/by-nc/4.0/.

\section{REFERENCES}

1. Kousky C. Impacts of natural disasters on children. Future Child 2016;26:73-92.

2. Cabinet Office, Government of Japan. White paper on disaster management. 2011. http://www.bousai.go.jp/kaigirep/hakusho/h23/ bousai2011/html/honbun/index.htm (accessed 8 Sep 2017).

3. Nelson S, Luten J, Jones K, et al. Mortality associated with Hurricane Katrina--Florida and Alabama, August-October 2005. MMWR Morb Mortal Wkly Rep 2006;55:239-42.

4. Jonkman SN, Maaskant B, Boyd E, et al. Loss of life caused by the flooding of New Orleans after Hurricane Katrina: analysis of the relationship between flood characteristics and mortality. Risk Anal 2009;29:676-98.

5. American Red Cross. American Red Cross \& Public Health: the response to hurricane katrina and beyond, report to ARC Disaster Health Services, March, 2006 Operation DR \# 865 Working Group on the American Red Cross Public Health Response to Hurricane. Katrina: The Harvard Humanitarian Initiative of Harvard School of Public Health. The John Hopkins Bloomberg School of Public Health.

6. Ushizawa H, Foxwell AR, Bice S, et al. Needs for disaster medicine: lessons from the field of the Great East Japan Earthquake. Western Pac Surveill Response J 2013;4:51-5.

7. Iwata O, Kawase A, Iwai M, et al. Evacuation of a Tertiary Neonatal Centre: Lessons from the 2016 Kumamoto Earthquakes. Neonatology 2017;112:92-6.

8. Osofsky J, Osofsky H. Lessons learned about the impact of disasters on children and families and post-disaster recovery. In: Culp A, ed. 
Child and family advocacy. Issues in clinical child psychology. New York: Springer, 2013:91-105.

9. Datar A, Liu J, Linnemayr S, et al. The impact of natural disasters on child health and investments in rural India. Soc Sci Med 2013;76:83-91.

10. Nakahara S, Ichikawa M. Mortality in the 2011 tsunami in Japan. $J$ Epidemiol 2013;23:70-3.

11. e-Stat, Portal Site of Official Statistics of Japan. Statistics of Japan. http://www.e-stat.go.jp/SG1/estat/eStatTopPortalE.do (Accessed 1 Sep 2017).

12. Data Warehouse for Healthcare and Welfare Plan. http://jmedicine. com/ (Accessed 21 Aug 2017).

13. Japan Medical Analysis Platform. http://jmap.jp/pages/guide (Accessed 21 Aug 2017).

14. Japan Association of Obstetricians and Gynecologists. http://www. jaog.or.jp/ (Accessed 21 Aug 2017).

15. Japanese Ministry of Health, Labour and Welfare. List of disasterready hospitals. http:// www.mhlw.go.jp/seisakunitsuite/bunya/ kenkou_iryou /iryou/saigai_iryou /dl/saigai_iryou07.pdf (Accessed 1 Sep 2017).

16. The National Police Agency. Damage situation and police countermeasures associated with 2011 Tohoku district - off the Pacific Coastal Earthquake. https://www.npa.go.jp/archive/keibi/ syouten/syouten281/pdf/ALL.pdf (Accessed 21 Aug 2017).

17. Chang KT. Geographic information system. In: Richardson D, Castree $\mathrm{N}$, Goodchild MF, eds. International encyclopedia of geography: people, the earth, environment and technology. New York: John Wiley \& Sons, 2017.

18. Esri. https://www.esri.com/en-us/home (Accessed 21 Aug 2017).

19. STATA. https://www.stata.com/stata14/ (Accessed 21 Aug 2017)

20. Sanuki R, Satoh E, Kumakawa T, et al. Accessibility to medical care in case of major disasters. Journal of the National Institute of Public Health 2013;62:52-61.

21. Eiji S, Toshiro K. Establishing medical care area from residents perspectives: The accessibility of critical care in Kanagawa Prefecture and Iwate Prefecture as case studies. Journal of the National Institute of Public Health 2013;62:46-51.

22. Masami I, Takashi N, Masami I. Emergency Medicine in Japan, JMA Policies. Japan Med Assoc J 2009;52:211-3.

23. General Services Administration Public Buildings Service, Child Care Division. Child Care Emergency Preparedness Toolbox. 2011. https:// www.gsa.gov/graphics/pbs/Child_Care_Emergency_Preparedness Toolbox.pdf (Accessed 21 Aug 2017).

24. Myung HN, Jang JY. Causes of death and demographic characteristics of victims of meteorological disasters in Korea from 1990 to 2008. Environ Health 2011:10:82

25. Mata-Lima H, Alvino-Borba A, Pinheiro A, et al. Impacts of natural disasters on environmental and socio-economic systems: what makes the difference? http://www.scielo.br/scielo.php?pid=S1414 753X2013000300004\&script=sci_arttext\&tIng=en\#nota (Accessed 21 Aug 2017). 